\title{
Clinical variability in patients with Apert's syndrome
}

Elisabeth Lajeunie, Ph.D., Rhoda Cameron, Ph.D., Vincent El Ghouzzi, Ph.D., Nathalie de Parseval, Ph.D., Pierre Journeau, M.D., Marie Gonzales, M.D., Anne-Lise Delezoide, M.D., Jacky Bonaventure, Ph.D., Martine Le Merrer, M.D., and Dominique Renier, M.D.

Services de Génétique, Neurochirurgie, Chirurgie Orthopédique, et Foetopathologie, Hôpital Necker-Enfants Malades, Paris, France; and Service d'Embryologie-Foetopathologie, Hôpital Saint-Antoine, Paris, France

Object. Apert's syndrome is characterized by faciocraniosynostosis and severe bony and cutaneous syndactyly of all four limbs. The molecular basis for this syndrome appears remarkably specific: two adjacent amino acid substitutions (either S252W or P253R) occurring in the linking region between the second and third immunoglobulin domains of the fibroblast growth factor receptor (FGFR)2 gene. The goal of this study was to examine the phenotype/genotype correlations in patients with Apert's syndrome.

Methods. In the present study, 36 patients with Apert's syndrome were screened for genetic mutations. Mutations were detected in all cases. In one of the patients there was a rare mutation consisting of a double-base pair substitution in the same codon (S252F). A phenotypical survey of our cases was performed and showed the clinical variability of this syndrome. The P253R mutation appears to be associated with the more severe forms of Apert's syndrome with regard to the forms of syndactyly and to mental outcome. In two patients there was no clinical or radiological evidence of craniosynostosis. In two other patients with atypical forms of syndactyly and cranial abnormalities, the detection of a specific mutation was helpful in making the diagnosis.

Conclusions. The fact that mutations found in patients with Apert's syndrome are usually confined to a specific region of the FGFR2 exon IIIa may be useful in making a diagnosis.

\section{Key Words * Apert's syndrome * FGFR2 mutation}

Apert's syndrome is the most clinically distinct type of craniosynostosis syndrome. The principal features are severe bicoronal craniosynostosis associated with proptosis, midfacial hypoplasia, and cutaneous and bony syndactyly of the hands and feet.[1] Most patients with Apert's syndrome are mentally retarded, but a minority do have normal intelligence. The surgical treatment, associated brain malformations, and the quality of the family environment have been shown to influence mental outcome in these patients.[14] The incidence of Apert's syndrome is approximately one in 50,000 births and most cases occur randomly.[5] It is worth noting that the number of affected children has decreased in the past 2 years because diagnostic fetal ultrasonography has given parents a choice regarding termination of pregnancy. 
This disorder has been associated with increased paternal age, and Moloney, et al.,[8] found that all mutations occur on the paternal chromosome. Two mutations have been reported in exon IIIa of the fibroblast growth factor receptor (FGFR)2 gene.[18] These missense mutations result in Ser252Trp or Pro253Arg.[13,18] The genotype/phenotype specificity of Apert's syndrome contrasts sharply with the wide range of mutations in Crouzon's and Pfeiffer syndromes. Park and colleagues[13] concluded that there were no differences between the two mutations with respect to their phenotypical features. In contrast, the severity of the syndactyly and the presence of cleft palate were correlated significantly with mutations in the series published by Slaney, et al.[17] In the present study, 36 patients with Apert's syndrome were screened for exon IIIa mutations, and the phenotype/genotype correlations were analyzed.

\section{CLINICAL MATERIAL AND METHODS}

\section{Clinical Analysis}

Blood from 36 patients with Apert's syndrome was made available for DNA analysis performed by the craniofacial unit of the Department of Pediatric Neurosurgery (33 children) and the fetopathological unit (three fetuses). Minimal criteria for all affected individuals included severe craniosynostosis, midfacial retrusion, ocular hypertelorism, proptosis, and syndactyly of the four limbs. The severity of the syndactyly was scored according to categories posited by Cohen and Kreiborg.[4] Type 1 is syndactyly of the central three digits; Type 2 is syndactyly of digits 2 through 5 , and Type 3 is syndactyly of all five digits. All patients underwent clinical and radiological studies, including magnetic resonance imaging in 31 cases. For the three fetuses, neuropathological data were available. The three fetuses were the second or the third gestation of unrelated parents; their availability was the result of therapeutic termination of pregnancy after prenatal diagnosis had been determined. The mental outcome of patients was determined using the classification of the World Health Organization (CIM-10. Classification statistique internationale des maladies et des problèmes de santé connexes. OMS, Genève, 1993), in which a normal intelligence quotient (IQ) is defined as an IQ greater than or equal to 70.

\section{Mutation Analysis}

Thirty-six patients with Apert's syndrome were screened by direct sequencing for mutations in exon IIIa (also called IIIu or 7) of the FGFR2 gene. Exon IIIa was amplified from genomic DNA by using the forward primer 5'-TGACAGCCCTCTGGACAACACAAC-3' and the reverse primer 5'-GGAAATCAAAGAACCTGTGGC-3' (both from intron sequences). A typical $50-\mu>1$ polymerase chain reaction consisted of $50 \mathrm{ng}$ genomic DNA, $1.5 \mathrm{mM} \mathrm{MgCl}_{2}, 0.2 \mathrm{mM}$ deoxynucleotide triphosphates, $100 \mathrm{ng}$ of each primer, and $1 \mathrm{U}$ Taq DNA polymerase (Boehringer Mannheim, Meylan, France). The cycling conditions included denaturation at $94 \check{\mathrm{s} C}$ for 30 seconds, annealing at $62 \check{\mathrm{s} C}$ for 40 seconds, and extension at $72 \check{\mathrm{s} C}$ for 30 seconds, for 30 cycles. The polymerase chain reaction product size was 349 bp. Samples were sequenced by using an automated DNA sequencer and a sequencing kit (Taq DyeDeoxy Terminator Cycle Sequencing kit with PE/ABd 373a DNA sequencers; Applied Biosystem, Courtaboeuf, France).

\section{RESULTS}

\section{The FGFR2 Mutation Analysis}

We examined the FGFR2 exon IIIa mutations from the genomic DNA of 36 patients with Apert's 
syndrome. We found three distinct mutations. In 23 patients $(64 \%)$, we found a $\mathrm{C} \rightarrow \mathrm{G}$ transversion resulting in a substitution of tryptophan for serine 252 (C934G). In 12 patients (33\%), the same transversion resulted in a substitution of arginine for proline 253 (C937G). In one fetus (Fig. 1), there was a double nucleotide substitution $(\mathrm{CG} \rightarrow \mathrm{TT})$ of residues 934 and 935, resulting in a substitution of serine 252 for phenylalanine. To be certain that one of the substitutions was not a polymorphism, we sequenced the exon IIIa of both parents of this fetus and found no difference from the published sequence (Genbank Accession No. M80634). Therefore, this was a de novo double mutation.

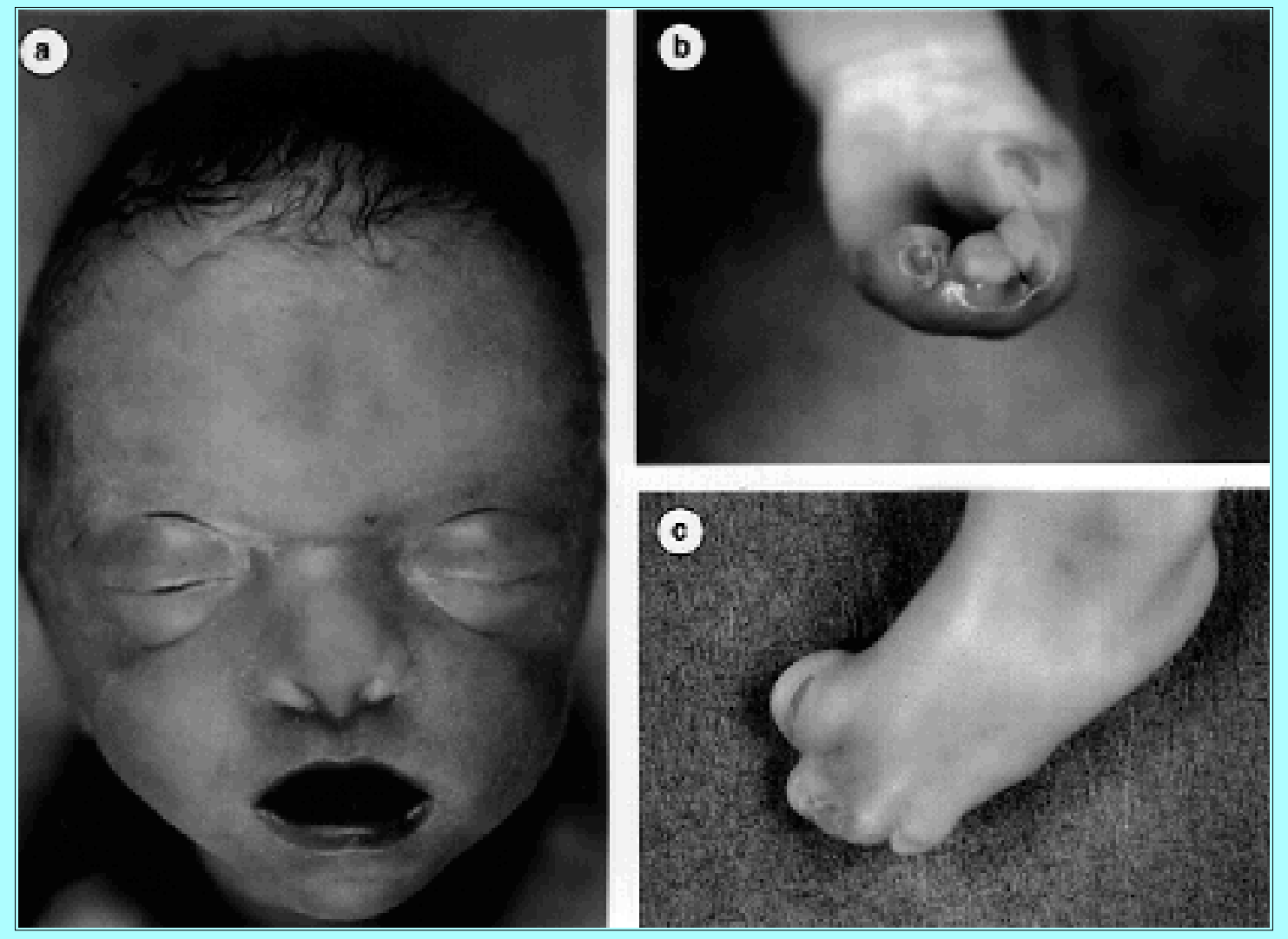

Fig. 1. Photographs showing the face (a), hand (b), and foot (c) of a fetus with Apert's syndrome.

\section{Clinical Analysis}

Considering the variable clinical expressivity of the disease and the narrow specific mutation spectrum of Apert's syndrome, we reassessed the clinical and radiological profiles of the patients based on the results of our genetic analysis. The clinical features of the patients are shown in Table 1. 


\begin{tabular}{|c|c|c|c|c|c|c|c|c|}
\hline & & CLINICA & L AND & $\begin{array}{l}\text { MOLECUL } \\
\text { APEI }\end{array}$ & $\begin{array}{l}\text { TABLE } 1 \\
\text { AR FIND NGS } \\
\text { T'S SYNDRO }\end{array}$ & 36 PATIEN & WITH & \\
\hline $\begin{array}{l}\text { Case } \\
\text { No. }\end{array}$ & $\operatorname{sex}$ & $\begin{array}{c}\text { Syrt } \\
\text { dactyy } \\
\text { Type }\end{array}$ & $\begin{array}{l}\text { Cleft } \\
\text { Padate }\end{array}$ & $\begin{array}{l}\text { Vert } \\
\text { triculo- } \\
\text { megaly }\end{array}$ & $\begin{array}{l}\text { Corpus } \\
\text { Callosum }\end{array}$ & $\begin{array}{l}\text { Septum } \\
\text { Pelluxidum }\end{array}$ & 10 & Mutation \\
\hline 1 & $\mathrm{~F}$ & 1 & - & - & normal & normal & 94 & 8252'n \\
\hline 2 & $M$ & 1 & + & - & hypoplasia & normal & 15 & 8252 ' \\
\hline 3 & $\mathrm{~F}$ & 1 & + & - & ageness & agenesis & NT & 8252 w \\
\hline 4 & $M$ & 1 & + & - & hypoplasia & normal & 50 & 8252 'W \\
\hline 5 & $\mathrm{~F}$ & 1 & - & - & normal & normal & 92 & 8252 W \\
\hline 6 & $M$ & 1 & - & - & normal & normal & 84 & 8252 ' \\
\hline 7 & $\mathrm{~F}$ & 1 & - & - & normal & normal & NT & 8252 W \\
\hline 8 & $M$ & 2 & - & - & normal & normal & NT & 8252' 'n' \\
\hline 9 & $M$ & 2 & - & - & normal & normal & NT & 8252 W \\
\hline 10 & $M$ & 2 & - & + & normal & cyst & 90 & 8252' 'n' \\
\hline 11 & $\mathrm{~F}$ & $\overline{2}$ & + & + & hypoplasia & agenesis & 114 & 8252 W \\
\hline 12 & $M$ & 2 & + & - & hypoplasia & cyst & NT & \$252' 'n \\
\hline 13 & $M$ & 2 & + & + & normal & nórmal & 71 & S252' \\
\hline 14 & $\mathrm{~F}$ & 2 & + & - & normal & normal & 60 & S252' \\
\hline $15 \dagger$ & $\mathrm{F}$ & $\overline{2}$ & + & - & agenesis & normal & NT & 8252 ' \\
\hline 16 & $M$ & 2 & + & + & hypoplasia & agenesis & 52 & 8252 ' \\
\hline 17 & $M$ & 2 & - & + & normal & cyst & 50 & S252' \\
\hline 18 & MI & 3 & - & - & hypoplasia & normal & NT & 8252 ' \\
\hline 19 & $\mathrm{~F}$ & 3 & & + & NT & $\mathrm{NT}$ & NT & 8252 ' \\
\hline 20 & MI & 3 & + & - & normal & normal & 36 & 8252 ' \\
\hline 21 & $\mathrm{~F}$ & 3 & + & + & normal & normal & 71 & S252'n \\
\hline 22 & $\mathrm{~F}$ & 3 & - & + & normal & cyst & 43 & S252W \\
\hline 23 & $M$ & 3 & + & - & normal & cyst & 81 & 8252 '心 \\
\hline $24 \dagger$ & $M$ & 3 & + & + & agenesis & normal & NT & S252F \\
\hline 25 & $\mathrm{~F}$ & 1 & - & - & normal & normal & 62 & P253R \\
\hline 26 & $\mathrm{~F}$ & 2 & - & - & normal & normal & 66 & P253R \\
\hline 27 & $M$ & $\overline{2}$ & - & + & normal & cyst & 60 & P253R \\
\hline 28 & $M$ & 2 & + & NT & $\mathrm{NT}$ & NT & 55 & P253R \\
\hline 29 & MI & $2 B$ & + & - & normal & normal & 25 & P253R \\
\hline 30 & MI & 3 & - & - & normal & cyst & 60 & P253R \\
\hline 31 & MI & 3 & - & - & normal & agenesis & 84 & P253R \\
\hline 32 & $\mathrm{~F}$ & 3 & - & - & normal & normal & 60 & P253R \\
\hline 33 & M & 3 & & - & normal & normal & NT & P253R \\
\hline 34 & $\mathrm{~F}$ & 3 & - & - & hypoplasia & normal & NT & P253R \\
\hline 35 & $M$ & 3 & - & + & hypoplasia & cyst & 60 & P253R \\
\hline $36 \dagger$ & $M$ & 3 & - & + & normal & normal & NT & P253R \\
\hline
\end{tabular}

Generally, craniofacial involvement was obvious at birth with symmetrical brachycephaly. We found some differences in the involvement of the synostosed sutures in some patients. In three patients (Cases 15, 16, and 35), both coronal sutures were fused; however, asymmetrical brachycephaly was evident. The patient in Case 21 had a plagiocephaly due to synostosis of the left coronal suture. The patient in Case 2 exhibited a more diffuse suture fusion in which both coronal and both lambdoid sutures were involved. Two patients (Cases 7 and 25) had no evidence of craniosynostosis, either clinically or radiologically. Cleft palate occurred in 12 of the 23 patients with the S252W mutation and in two of the 12 patients with the P253R mutation (Fisher's exact test: $\mathrm{p}<0.05$ ). The fetus with the S252F mutation also had a cleft palate. Thus, the overall frequency of cleft palate in this series was $42 \%$ ( 15 of 36 cases). Four patients (Cases 2, 3, 14, and 31) had a choanal atresia, which had necessitated a tracheotomy in two of them.

Magnetic resonance imaging was not available in two patients (Cases 19 and 28). Partial or complete 
agenesis of the corpus callosum was the major abnormality of the central nervous system and was present in eight of 22 patients with the S252W mutation in two of 11 patients with the P253R mutation (difference was nonsignificant). A cyst or agenesis of the septum pellucidum was present in eight of 22 patients (excluding fetuses) with the S252W mutation and in four of 11 patients with the P253R mutation (difference was nonsignificant). The size of the ventricles was increased in 12 cases. Among the patients with dilated ventricles, eight were classified as having nonprogressive ventriculomegaly and four as having progressive hydrocephalus; shunts were placed in the latter group. The patient in Case 2 had a lambdoid synostosis and a Chiari I malformation (an unusual feature in cases of Apert's syndrome, as compared with cases of Crouzon's syndrome[3]); this case had the classic S252W mutation.

Neuropathological data were available in the three fetuses (Cases 15, 24, and 36). Abnormal gyration of the temporal lobe with dysgenesis of the parahippocampal area, resembling neuropathological findings in patients affected with thanatophoric dysplasia, were observed.

Mental level was assessed in 24 patients. Fifteen of these had an IQ less than 70. The IQ was less than 70 in seven of 15 patients with the S252W mutation and in eight of nine patients with the P253R mutation (Fisher's exact test: $\mathrm{p}<0.05$ ).

Severe syndactyly (Type 3) occurred more frequently in patients with the P253R mutation (eight of 12) than in those with the S252W mutation (six of 23) (Fisher's exact test: $\mathrm{p}<0.03$ ). In one patient who had the P253R mutation (Case 29), the right hand was Type 2, whereas the left hand was Type 3. Two patients (Cases 3 and 4 ) had a particular Type 1 syndactyly that consisted merely of cutaneous fusion (Fig. 2).

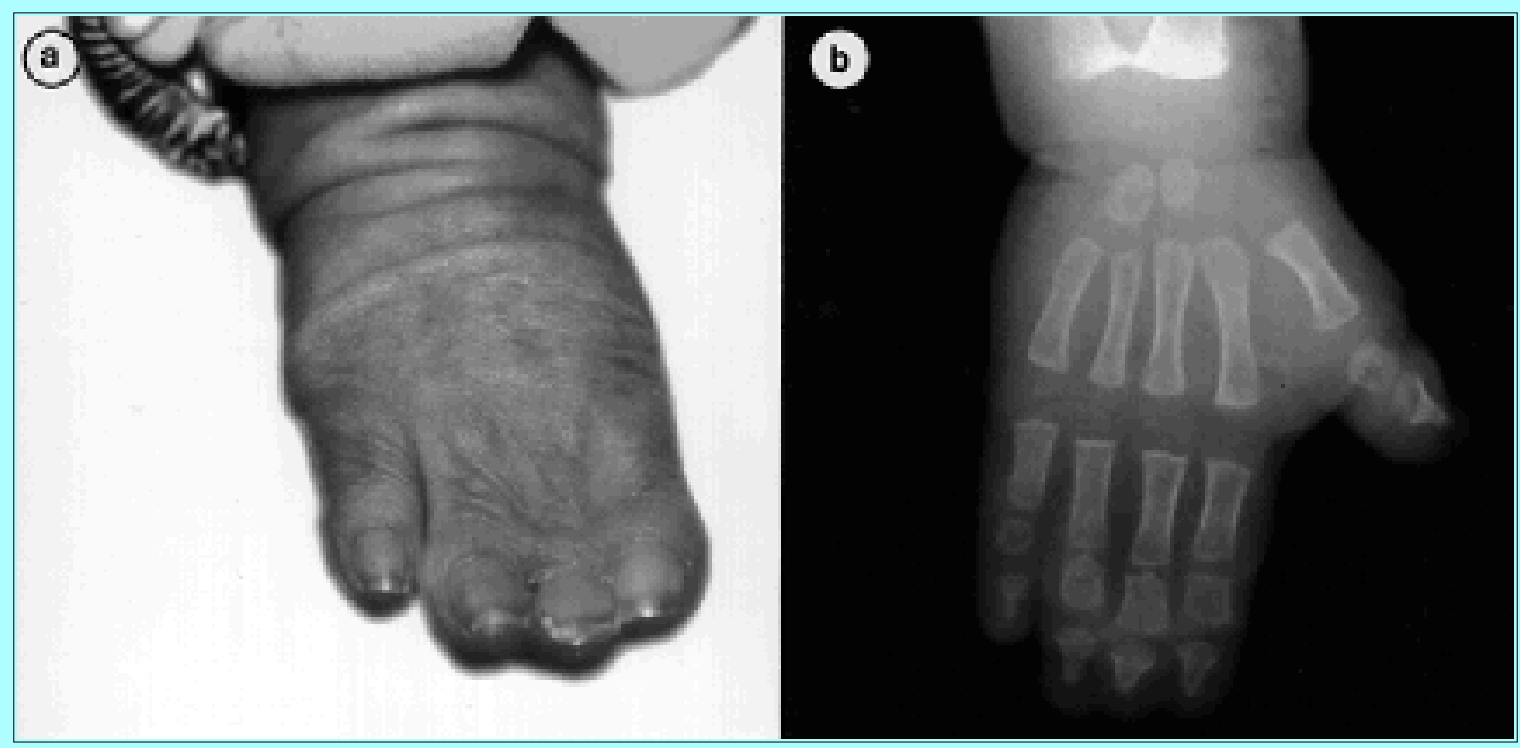

Fig. 2. Photograph (a) and radiograph (b) showing the hand of a patient with Apert's syndrome.

In $75 \%$ of the patients x-ray films of feet were available. In all cases, the type of syndactyly was identical to, or more severe than, that of the hands. However, two of the patients had a rudimentary sixth toe and three others had a supernumerary delta phalanx between the first and the second toes on both feet (Fig. $3)$. 


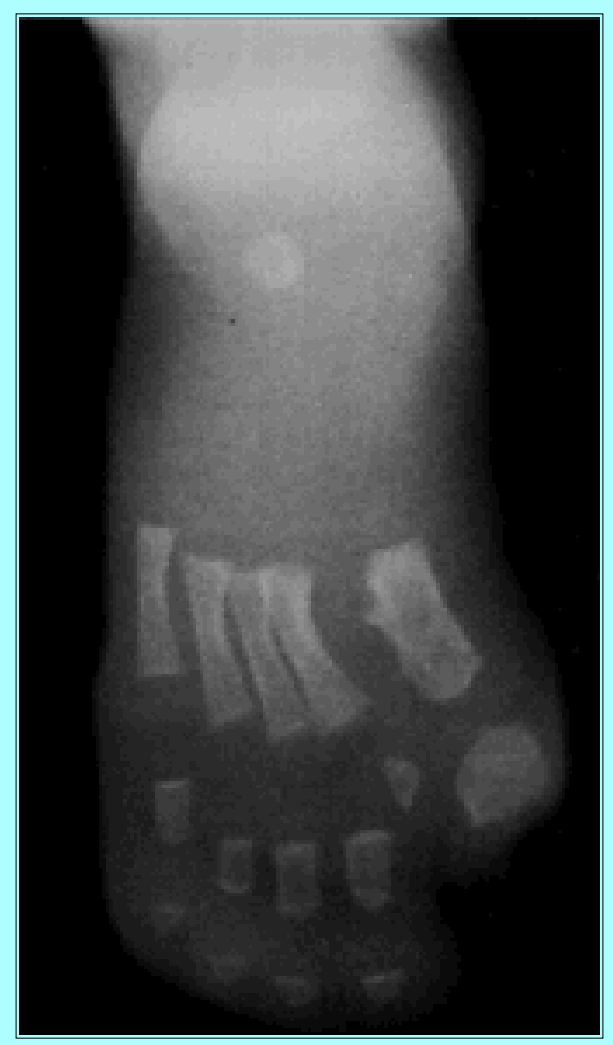

Fig. 3. Radiograph showing the foot of a patient with Apert's syndrome.

\section{DISCUSSION}

This study of FGFR2 mutations in 36 patients with Apert's syndrome confirms that the mutations are restricted to two codons. The compilation of our results and those of previous molecular studies[7,8,11,13,18] is presented in Table 2. Of 203 patients, the proportion of the two types of mutation is $65 \% \mathrm{~S} 252 \mathrm{~W} / 34 \% \mathrm{P} 253 \mathrm{R}$. The small number of mutated codons is in sharp contrast with the multiple mutation sites of FGFR2 seen in other craniosynostosis syndromes such as Crouzon's, Pfeiffer, and Jackson-Weiss.[6,7,9,11] This specificity of mutation sites and the high mutation rate can be compared with the mutation of FGFR3 seen in achondroplasia.[2,15,16]

\begin{tabular}{|c|c|c|c|c|c|}
\hline \multicolumn{6}{|c|}{$\begin{array}{c}\text { TABLE } 2 \\
\text { REVIEW OF STUDIES ON MUTATIONS IN A.PERT'S SYNDROME* }\end{array}$} \\
\hline \multirow[b]{2}{*}{ Authors \& Year } & \multirow{2}{*}{$\begin{array}{l}\text { No. of } \\
\text { Patients }\end{array}$} & \multicolumn{4}{|c|}{ Mutation } \\
\hline & & $\mathrm{S} 252 \mathrm{~W}$ & $\mathrm{~S} 252 \mathrm{~F}$ & $\mathrm{P} 253 \mathrm{R}$ & Other \\
\hline Park, et al., 1995 & 35 & 25 & - & 9 & 1 \\
\hline Meyers, et al., 1996 & 13 & 9 & - & 4 & - \\
\hline Moloney, et al., 1996 & 118 & 74 & - & 44 & - \\
\hline Odridge, et al., 1997 & 1 & - & 1 & - & - \\
\hline present study & 36 & 23 & 1 & 12 & - \\
\hline
\end{tabular}

A fetus with Apert's syndrome had a double nucleotide substitution $(\mathrm{CG} \rightarrow \mathrm{TT})$ that predicted a serine $252 \rightarrow$ phenylalanine substitution. This mutation has been reported in only one other case[10] and its rarity (two of 203 cases) could be explained by the requirement that two residues of the serine codon be mutated simultaneously. 
The analysis of phenotype in our study shows that there were significant differences in the frequency of cleft palate in the patients with the S252W mutation and in the severity of syndactyly in the patients with the P253R mutation. With regard to the latter finding, our study shows that patients with P253R have a higher probability of suffering from more severe syndactyly, although some S252W patients also had Type 3 syndactyly. As far as mental outcome is concerned, patients with the P253R mutation also appeared be more severely affected compared with those with the S252W mutation. Because other prognostic factors[14] were equally distributed in the two groups, especially the way in which these patients were treated, this raises the question of the role of the P253R mutation in the mental outcome of patients who have Apert's syndrome.

The pathogenetic mechanism of Apert's syndrome mutations is not presently understood. The results of preliminary studies confirm that murine FGFR2 is expressed in cranial sutures.[12] We have two patients carrying a mutation in whom there is no craniosynostosis, but evident midfacial flattening and syndactyly of the hands and feet, suggesting a diagnosis of Apert's syndrome. This finding suggests an involvement of the FGF/FGFR pathway in limb morphogenesis.

Usually, the diagnosis of Apert's syndrome is easy to determine, based on clinical findings. However, in some rare cases, such as Case 2 in the present study, one of the essential diagnostic features can be missing (osseous fusion of the phalanges). Other syndromes with acrocephalosyndactyly could therefore be discussed, but the detection of a typical mutation of Apert's syndrome ensured the diagnosis and emphasized the variable expressivity of the disease. Because the mental outcome in patients with Apert's syndrome is much worse than that in patients with other types of acrocephalosyndactyly, the diagnosis is important to discuss the prognosis. The fact that the mutations in patients with Apert's syndrome are confined to a specific region of FGFR2 exon IIIa in $99 \%$ of the cases may be useful in making the diagnosis. Prenatal diagnosis may allow for genetic counseling in difficult cases.

\section{Acknowledgments}

We gratefully acknowledge Drs. Paul Dominic Chumas and Peter Diriks for reviewing the manuscript.

\section{References}

1. Apert E: De l'acrocéphalosyndactylie. Bull Mem Soc Med Hop 243:1310-1330, 1906

2. Bellus GA, McIntosh I, Smith EA, et al: A recurrent mutation in the tyrosine kinase domain of the fibroblast growth factor receptor 3 causes hypochondroplasia. Nat Genet 10:357-359, 1995

3. Cinalli G, Renier D, Sebag G, et al: Chronic tonsillar herniation in Crouzon's and Apert's syndromes: the role of the premature synostosis of the lambdoid suture. J Neurosurg 83:575-582, 1995

4. Cohen MM Jr, Kreiborg S: Hands and feet in the Apert syndrome. Am J Med Genet 57:82-96, 1995

5. Cohen MM Jr, Kreiborg S, Lammer EJ, et al: Birth prevalence study of the Apert syndrome. Am J Med Genet 42:655-659, 1992

6. Lajeunie E, Ma HW, Bonaventure J, et al: FGFR2 mutations in Pfeiffer syndrome. Nat Genet 9:108, 1995 (Letter)

7. Meyers GA, Day D, Goldberg R, et al: FGFR2 exon IIIa and IIIc mutations in Crouzon, 
Jackson-Weiss, and Pfeiffer syndromes: evidence for missense changes, insertions, and a deletion due to alternative RNA splicing. Am J Hum Genet 58:491-498, 1996

8. Moloney DM, Slaney SF, Oldridge M, et al: Exclusive paternal origin of new mutations in Apert syndrome. Nat Genet 13:48-53, 1996

9. Muenke M, Schell U, Hehr A, et al: A common mutation in the fibroblast growth factor receptor 1 gene in Pfeiffer syndrome. Nat Genet 8:269-274, 1994

10. Oldridge M, Lunt PW, Zackai EH, et al: Genotype-phenotype correlation for nucleotide substitution in the IgII-IgIII linker of FGFR2. Hum Mol Genet 6:137-143, 1997

11. Oldridge M, Wilkie AOM, Slaney SF, et al: Mutations in the third immunoglobulin domain of the fibroblast growth factor receptor-2 gene in Crouzon syndrome. Hum Mol Genet 4:1077-1082, 1995

12. Orr-Urtreger A, Givol D, Yayon A, et al: Developmental expression of two murine fibroblast growth factor receptors, flg and bek. Development 113:1419-1434, 1991

13. Park WJ, Theda C, Maestri NE, et al: Analysis of phenotypic features and mutations in Apert syndrome. Am J Hum Genet 57:321-328, 1995

14. Renier D, Arnaud E, Cinalli G, et al: Prognosis for mental function in Apert's syndrome. J Neurosurg 85:66-72, 1996

15. Rousseau F, Bonaventure J, Legeai-Mallet L, et al: Mutations in the gene encoding fibroblast growth factor receptor-3 in achondroplasia. Nature 371:252-254, 1994

16. Shiang R, Thompson LM, Zhu YZ, et al: Mutations in the transmembrane domain of FGFR3 cause the most common genetic form of dwarfism, achondroplasia. Cell 78:335-342, 1994

17. Slaney SF, Oldridge M, Hurst JA, et al: Differential effects of FGFR2 mutations on syndactyly and cleft palate in Apert syndrome. Am J Hum Genet 58:923-932, 1996

18. Wilkie AOM, Slanay SF, Oldridge M, et al: Apert syndrome results from localized mutations of FGFR2 and is allelic with Crouzon syndrome. Nat Genet 9:165-172, 1995

Manuscript received June 23, 1998.

Accepted in final form October 28, 1998.

Address reprint requests to: Dominique Renier, M.D., Neurochirurgie, Hôpital Necker-Enfants Malades, 149 rue de Sèvres, 75743 Paris Cedex 15, France. email: renier@easynet.fr. 